\title{
FUTURE CLIMATE CHANGE AND ITS INFLUENCE ON MILK PRODUCTION OF HOLSTEIN CATTLE MAINTAINED IN THE NILE DELTA OF EGYPT
}

\author{
R.R. Sadek ${ }^{1}$, A.A. Nigm ${ }^{1}$, Sherien A. Yassien ${ }^{2}$, M.A.M. Ibrahim ${ }^{1}$ and M. A. El-Wardani ${ }^{2}$ \\ 1- Department of Animal Production, Faculty of Agriculture, Cairo University, Giza, Egypt \\ 2-Department of Production Systems Research, Animal Production Research Institute, Agricultural \\ Research Center, Dokki, Egypt
}

\section{SUMMARY}

The objectives of the present study were to develop a simplified equation to estimate temperature-humidity index (THI) under the Egyptian conditions and to assess the influence of expected climate change on test-day milk yield of Holstein cattle in the Nile Delta of Egypt in the years 2025 and 2050. Data of air temperature (AT) and relative humidity $(R H)$ throughout the period from 2000 to 2014 and of their expected corresponding values in the two years 2025 and 2050 were provided by the Central Laboratory for Agricultural Climate (CLAC). Meteorological data between the years 2000 - 2014 were used to detect if there was an ascending trend in THI of Nile Delta of Egypt throughout this period. Meteorological data of the years 2025 and 2050 were used to estimate the THI of these two years relative to the year 2000 as a benchmark.

Using regression technique, a new accurate and simplified equation was developed to estimate THI. The equation accounted for $99.5 \%$ of the variance of THI. The developed equation was used to predict THI in the years 2025 and 2050. A total of 109759 test-day milk yield (TDMY) records for 5546 Holstein cows located in four herds was used to establish the effect of THI on TDMY of Holstein cattle in the Delta region.

Meteorological data indicated a considerable increase in THI by $13.9 \%$ (78.8) and 17.3\% (81.2) for the years of 2025 and 2050, respectively, relative to the year 2000 (69.2). Analysis of TDMY indicated a significant decrease of $0.12 \mathrm{~kg}(1.2 \%)$ for each increase of one THI unit above 74 under the current managerial practices.

The study concluded that proper and prompt breeding, feeding and system modifications should be considered to counteract the expected increase in THI by the years 2025 and 2050, to restore milk production of Holstein cattle in the Nile Delta of Egypt.

\section{Keywords: climate change, temperature-humidity index, milk production, Holstein}

\section{INTRODUCTION}

Global warming is one of the inconvenient scenarios that may face man kind in the third millennium, due to the negative impacts of the expected high temperature on agriculture, environment and health (Houghton et al., 2001; Nardone et al., 2006 and Singh et al., 2012). However, no quantitative assessment of future impact of the global warming has been undertaken under the Egyptian conditions.

Dairy production is an important business in agriculture sector, where a large investment is already allocated in. It is expected that dairy production business will be expanded in the future due to the gap in animal protein consumption / capita, the market needs and expansion in dairy processing industry. Holstein is the most recognized and common dairy breed (Elischer, 2014); the most predominant exotic breed in the commercial herds in Egypt; and the most vulnerable to heat stress and the current climate change (Thornton et al., 2009).

Nile Delta is considered the most appropriate area in Egypt to maintain the high yielding Holstein cattle due to its moderate air temperature compared to Mid - and Upper Egypt. As a part of Egypt, this region is expected to suffer from the assumed global warming (Elsharkawy et al., 2009; Sterman, 2009 and El Raey, 2010). This region is characterized by relatively low land relative to sea level, which leaves it suffers severely exposed to drowning by sea water. This expectation is drawn from the expected increase of sea level by about 2 millimeters annually at Alexandria to about 2.5 millimeters annually at Port Said (Stanley and Warne, 1993).

Temperature-humidity index (THI) has been recommended as an applicable indicator of heat stress and climate change as well (Ravagnolo et al., 2000; Ghavi Hossein-Zadeh et al., 2013 and Nigm et al., 2015). Many equations are applied to estimate the THI (NOAA, 1976; Mader et al., 2006 and Ghavi Hossein-Zadeh et al., 2013). Despite the existing equations to estimate THI are widely used, no single equation was tested under the Egyptian conditions.

The simulation trials of Perkins (2012) and Yirka (2012) expected a rise of 1.4 to $3{ }^{\circ} \mathrm{C}$ in the global air temperature by the year 2050. Nigm et al. (2015) confirmed a marked increase in THI of the Delta region of Egypt, starting the year 2011 up to 2014. This increase resulted in decreasing milk production compared to the period from 2000 to 2010 for the same genotype under the same housing system and managerial practices. Up to the knowledge of the authors, no research works have dealt with the futuristic impact of global warming on milk production of Holstein in this region.

The objectives of this study were to develop an equation to estimate THI under prevailing Egyptian conditions and to assess the effect of climate change on test-day milk yield of Holstein cattle in the Delta of Egypt in the years 2025 and 2050. 


\section{MATERIALS AND METHODS}

Milk production data:

The source of the milk production data (location, farms, genotype and managerial practices) was described in detail by Nigm et al. (2015). Test-day milk yield (TDMY) was recommended to be the best measurement of the milk produced by a cow over a period of $24 \mathrm{~h}$ (Schaeffer and Jamrozik, 1996). Thus, it was used to measure total milk production in the four studied herds, over a 15-year period (2000-2014, inclusive). Data of TDMY were used to study the effect of increasing THI units (more than 74, according to Mader et al., 2006) on TDMY of Holstein cattle in the Delta region.

\section{Meteorological data:}

Meteorological data (air temperature, AT and relative humidity, RH) of El- Behera, El-Sharkia and Kafr El-Sheikh governorates (the four herds locations) were obtained from the Central Laboratory for Agricultural Climate (CLAC), Agricultural Research Center, Ministry of Agriculture and Land Reclamation, Egypt. The data comprised the actual AT and RH between the years 2000 and 2014 to build up the model of a new equation for estimating THI, and the predicted meteorological data (AT and RH) for the two years 2025 and 2050 in the same governorates under study to estimate the THI in the years 2025 and 2050.

Geographical seasons of Egypt were classified as: Winter (S1), from December to February; Spring (S2), from March to May; Summer (S3), from June to August and Autumn (S4), from September to November to identify the months of highest values of THI across the period of 2000-2014.

\section{Statistical analysis:}

Data of the TDMY were analyzed using XLSTAT (2015). Linear regression technique was used to assess the effect of increasing THI on TDMY.

The Variable Importance for Projection (VIP) and regression analysis program were used to develop the new equation presumed to estimate THI. The two independent variables incorporated were the averages of both AT and RH.

The model applied to assess the influence of climate change on TDMY in the years 2000, 2025 and 2050 reads:

$\mathrm{Y}_{\mathrm{ijk}}=\mu+\mathrm{H}_{\mathrm{i}}+\mathrm{R}_{\mathrm{j}}+(\mathrm{HR})_{\mathrm{ij}}+\mathrm{e}_{\mathrm{ijk}}$

Where,

$\mathrm{Y}_{\mathrm{ijk}}=$ an observation of the test day milk yield trait, $\mu=$ the overall mean,

$\mathrm{H}_{\mathrm{i}}=$ effect of $\mathrm{i}^{\text {th }}$ herd, $(\mathrm{i}=1,2,3$ and 4$)$, where $1=$ Dina $1,2=$ Dina 2, $3=$ Samy Asaad and $4=$ ElKarada,

$R_{j}=$ effect of $j^{\text {th }}$ year, $(j=1,2$ and 3$)$, where $1=2000$, $2=2025$ and $3=2050$,

$\mathrm{HR}_{\mathrm{ij}}=$ effect of the interaction between herd and year, and

$\mathrm{e}_{\mathrm{ijk}}=$ random error, assumed to be $\operatorname{NID}\left(0, \sigma^{2}\right)$.

\section{RESULTS AND DISCUSSION}

\section{Developing a new equation to calculate THI:}

The present developed equation for estimating THI under the Egyptian climatic conditions reads: $\mathrm{THI}=32.783+1.478 \times \mathrm{AT}+0.056 \times \mathrm{RH}$

Where: 32.783 is the intercept, 1.478 is the regression of THI on AT, 0.056 is the regression of THI on RH, AT is the average of air temperature $\left({ }^{\circ} \mathrm{C}\right)$ and $\mathrm{RH}$ is the average of relative humidity $(\%)$. The accuracy of this equation $\left(R^{2}\right)$ is 0.995 .

The new equation was compared with three other extensively cited equations for estimating THI; (1) National Oceanic and Atmospheric Administration (NOAA, 1976); (2) Mader et al. (2006) and (3) Ghavi Hossein-Zadeh et al. (2013). The four equations were tested on 540 records of AT and RH to estimate THI. The comparison revealed that all equations have the same mean and standard deviation (Table 1).

The correlation matrix (Pearson) between the new equation and those of the above-mentioned equations ranged from 0.996 to 0.997 (Table 2).

Table 1. Descriptive statistics of THI calculated by different equations

\begin{tabular}{lccccc}
\hline Equations & No* & Min. & Max. & Mean & SD \\
\hline NOAA (1976) & 540 & 52.8 & 82.2 & 67.4 & 5.3 \\
Mader et al. (2006) & 540 & 52.8 & 82.3 & 67.4 & 5.3 \\
Ghavi Hossein-Zadeh et al. (2013) & 540 & 52.8 & 82.3 & 67.4 & 5.3 \\
The present equation & 540 & 52.9 & 81.0 & 67.4 & 5.3 \\
\hline
\end{tabular}

THI is the temperature-humidity index.

* $540=3$ governorates $\times 15$ years x 12 months.

NOAA is the National Oceanic and Atmospheric Administration.

Table 2. Correlation matrix (Pearson) among the present THI equation (4) and the equations of NOAA (1976) (1), Mader et al. (2006) (2) and Ghavi Hossein-Zadeh et al. (2013) (3)

\begin{tabular}{ccccc}
\hline Equation & $\mathbf{1}$ & $\mathbf{2}$ & $\mathbf{3}$ & $\mathbf{4}$ \\
\hline $\mathbf{1}$ & 1 & 1.000 & 1.000 & 0.996 \\
$\mathbf{2}$ & & 1 & 1.000 & 0.997 \\
$\mathbf{3}$ & & 1 & 0.996 \\
$\mathbf{4}$ & & & 1 \\
\hline
\end{tabular}

All values are different from 0 with a significance level alpha $=0.05$.

THI is the temperature-humidity index.

NOAA is the National Oceanic and Atmospheric Administration. 
From the above-mentioned results, it could be concluded that the new equation can be used for accurate estimation of THI under the climatic conditions of the Egyptian Delta region.

\section{Indicators of climate change (2000-2014):}

Under the Egyptian circumstances, Nigm et al. (2015) proved an increase in the average of THI values during the summer months of Egypt (S3) across the years 2000 to 2014 , in the same three studied governorates of the Delta region. Heat stress in summer was reported to affect milk yield and reproduction (Ghavi Hossein-Zadeh et al., 2013).

Estimating the THI during the geographical seasons of Egypt using the new developed equation as proposed in this study indicated that S3 surpassed THI of 74 (normal area of THI) starting the year 2011 till the year 2014 (alert area, $74<\mathrm{THI}<79$, Figure 1).

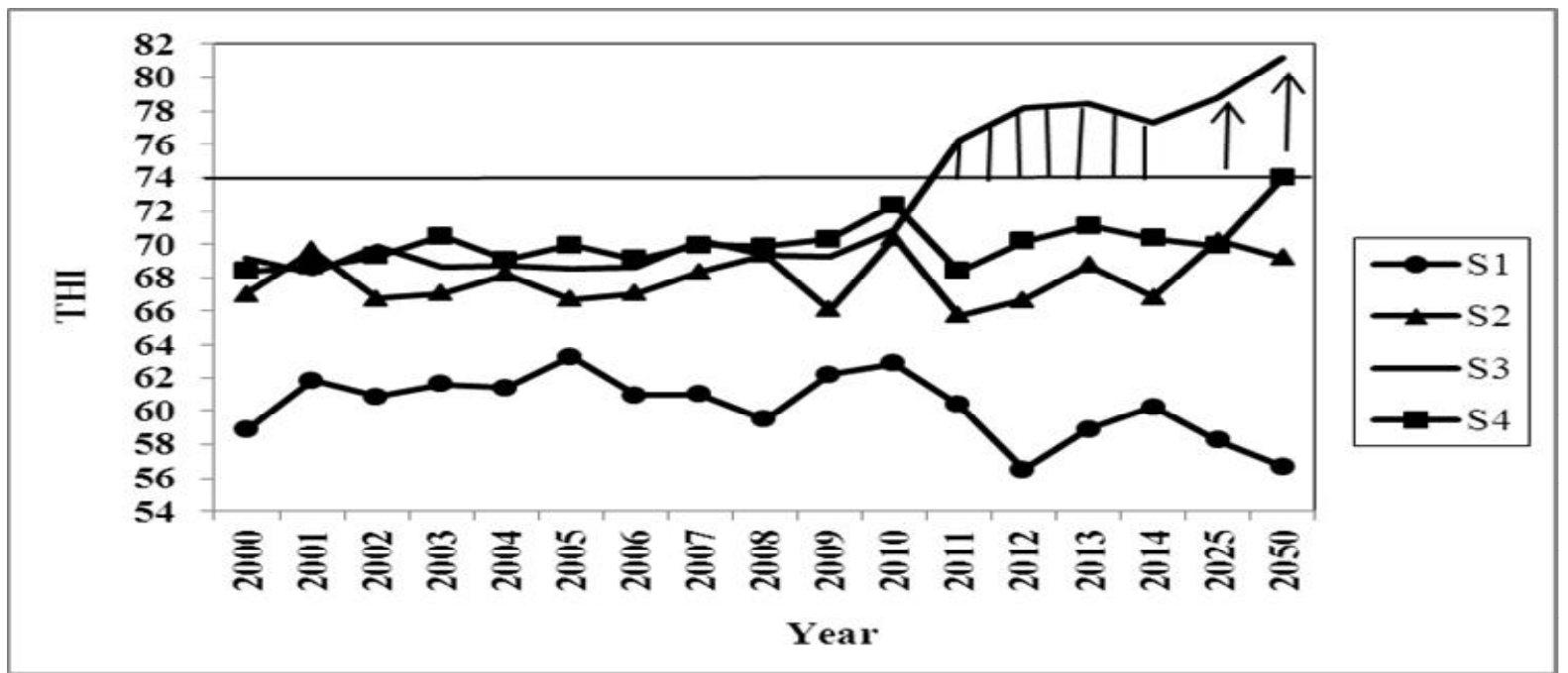

Fig. 1. Climate change in Nile Delta from the year 2000 till 2050 as expected by the new equation; S1 = Dec.-Feb.; S2 = March-May; S3 = June-Aug. and S4 = Sept.-Nov.

\section{Expected future climate change:}

Meteorological data indicated that AT in the Nile Delta of Egypt is expected to increase, which will be reflected with no doubt, on THI values. Near (2025) and far future climate change (2050) are presented in Table (3). In comparison with the year 2000, it is quite clear that AT will increase by 33.0 and $40.7 \%$ for the years 2025 and 2050, respectively. On the contrary, RH will decrease by 33.2 and $34.4 \%$ for the years 2025 and 2050, respectively. This will result in an increase in THI values by 13.9 and $17.3 \%$ for the years 2025 and 2050, respectively (Table 3). According to Mader et al. (2006), THI in the year 2025 will be very close to the danger area, and in the year 2050 will attain the danger area $(79 \leq \mathrm{THI}<84)$ which needs different managerial practices to be faced.

Table 3. Average AT, RH and THI values* and rate of change in the hottest season (June-August) in Egypt in different years as provided by CLAC (measured by the new equation) relative to the year 2000

\begin{tabular}{lccc}
\hline & \multicolumn{3}{c}{ Year } \\
\cline { 2 - 4 } Trait & 2000 & 2025 & $\mathbf{2 0 5 0}$ \\
\hline Average AT & 22.1 & 29.4 & $\mathbf{3 1 . 1}$ \\
Average RH & 68.0 & 45.4 & $\mathbf{8 1 . 2}$ \\
Average THI & 69.2 & 78.8 & 40.7 \\
Rate of AT change (\%) & - & 33.0 & -34.4 \\
Rate of RH change (\%) & - & -33.2 & 17.3 \\
Rate of THI change (\%) & - & 13.9 & \\
\hline
\end{tabular}

CLAC is the Central Laboratory for Agricultural Climate, Agricultural Research Center, Ministry of Agriculture and Land Reclamation, Egypt.

AT is the air temperature in ${ }^{\circ} \mathrm{C}, \mathrm{RH}$ is the relative humidity in absolute value and THI is the temperature-humidity index, ${ }^{*}$ Calculated using 10731 observations of the hottest season.

It is worthy to underline that, the changes in AT between the year 2000 and $2025(33.0 \%)$ was greater than the corresponding change between the year 2025 and $2050(7.7 \%)$. Similar trend was observed for THI $(13.9 \%)$ between the year 2000 and 2025 and (3.4\%) between the year 2025 and 2050 . The opposite trend was observed for $\mathrm{RH}$, and the changes from the year 2000 and 2025 was $(-33.2 \%)$, decreased to $-1.2 \%$ from the year 2025 and 2050 .

\section{Effect of THI on TDMY:}


Collected data of TDMY from the year 2000 to 2014 of the four herds indicated that TDMY started to decline in the year 2011 when THI exceeded the threshold of normal area and entered the alert area in the hottest season (Figure 2).

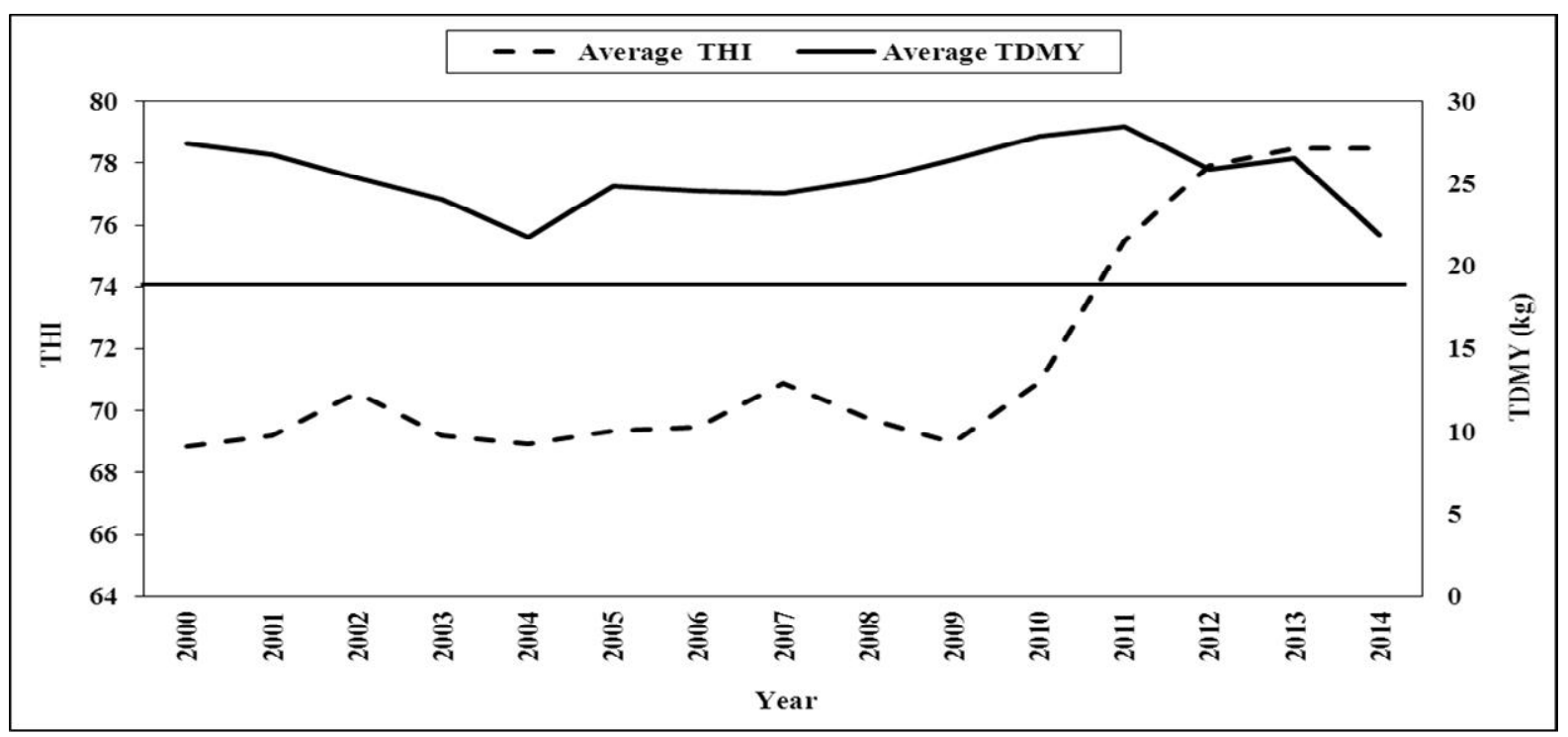

Fig. 2. Effect of temperature-humidity index (THI) on test-day milk yield (TDMY) in the hottest season (June-August) throughout all years of the study

Decline in TDMY was found to be $0.12 \mathrm{~kg} / \mathrm{day}$ (1.2\%) for each increase of one unit THI above 74 . This estimate of decline was much less than those reported by Ravagnolo et al. (2000) in Georgia, USA who estimated that milk yield decreased by 0.2 $\mathrm{kg} /$ day per unit increase in the THI values $\geq 72$. Similar trend was observed by Bouraoui et al. (2002) in Tunisia who estimated that milk yield decreased by $0.41 \mathrm{~kg} /$ day for each unit increase in the THI values above 69 . The obtained low decrease in milk production per each unit increase of THI $(120 \mathrm{~g})$ relative to those reported by Ravagnolo et al. (2000) and Bouraoui et al. (2002) is most probably attributed to that the THI of micro-environment in Dina 1 and Dina 2 were actually less than the estimated THI of macro-environment, where, the cows' housing yards were equipped with efficient cooling system (Ashour et al., 2014 and Sadek et al., 2014) to keep the THI under the sheds of the yards below 74 .

The expected decrease in TDMY in the years 2025 and 2050 is most probably attributed to the reduction in feed intake and the physiological effort for heat dissipation (Kadzere et al., 2002).

The analysis of TDMY and THI data in the years 2000, 2025 and 2050 showed that herd, year and the interaction between herd and year had a significant effect $(\mathrm{P}<0.0001)$ on THI and subsequently TDMY.

Table 4. Least squares means ${ }^{1}$ and standard errors of TDMY and THI as affected by the interaction between herd and year in the hottest season (June-August)

\begin{tabular}{|c|c|c|c|c|c|c|}
\hline \multirow{3}{*}{ Herd } & \multicolumn{6}{|c|}{ Year } \\
\hline & \multicolumn{2}{|c|}{2000} & \multicolumn{2}{|c|}{2025} & \multicolumn{2}{|c|}{2050} \\
\hline & TDMY & THI & TDMY & THI & TDMY & THI \\
\hline \multirow[t]{2}{*}{ Dina 1} & $28.5^{\mathrm{a}}$ & $68.8^{i}$ & $27.3^{b}$ & $78.4^{\mathrm{f}}$ & $27.1^{b}$ & $80.4^{c}$ \\
\hline & \pm 0.126 & \pm 0.021 & \pm 0.126 & \pm 0.021 & \pm 0.126 & \pm 0.021 \\
\hline \multirow[t]{2}{*}{ Dina2 } & $28.9^{\mathrm{a}}$ & $68.8^{\mathrm{i}}$ & $27.7^{\mathrm{b}}$ & $78.4^{\mathrm{f}}$ & $27.5^{\mathrm{b}}$ & $80.4^{c}$ \\
\hline & \pm 0.334 & \pm 0.055 & \pm 0.334 & \pm 0.055 & \pm 0.334 & \pm 0.055 \\
\hline \multirow[t]{2}{*}{ Samy Asaad } & $19.1^{\mathrm{c}}$ & $69.7^{\mathrm{g}}$ & $18.0^{\mathrm{d}}$ & $79.2^{\mathrm{d}}$ & $17.5^{\mathrm{d}}$ & $83.0^{\mathrm{a}}$ \\
\hline & \pm 0.253 & \pm 0.042 & \pm 0.253 & \pm 0.042 & \pm 0.253 & \pm 0.042 \\
\hline \multirow[t]{2}{*}{ El-Karada } & $12.8^{\mathrm{e}}$ & $69.2^{\mathrm{h}}$ & $11.6^{\mathrm{e}}$ & $78.9^{\mathrm{e}}$ & $11.4^{\mathrm{e}}$ & $80.8^{\mathrm{b}}$ \\
\hline & \pm 0.674 & \pm 0.111 & \pm 0.674 & \pm 0.111 & \pm 0.674 & \pm 0.111 \\
\hline
\end{tabular}

TDMY is the test-day milk yield and THI is the temperature-humidity index measured by the new equation.

${ }^{1}$ Means, within each row and within each column, followed by different letters, differ significantly $(\mathrm{P}<0.05)$.

The interaction between herd and year shows that, El-Karada was the lowest in TDMY whatever the year was, and there was no significant difference in TDMY within years (Table 4). In all other three herds, there was a significant difference $(\mathrm{P}<0.05)$ in TDMY between the year 2000 in one hand and the other two years 2025 and 2050 on the other hand. This finding agreed with Berman (2005), who stated 
that the low-producing cows were affected by heat stress less than the high-producing ones. The significant decrease in TDMY in Dina 1 and Dina 2 by the years 2025 and 2050 was unexpected. This unexpected trend is due to that these two herds were well equipped with effective cooling system. This means that such cooling facilities may need more development to face the higher rise of THI in 2025 and 2050 .

Moreover, earth warming will alter heat exchange between animal and environment (Thornton et al., 2009). This alteration will not be affecting milk production and feed intake only, but will also affect mortality rate, growth and productivity of livestock. Thornton et al. (2009) added also that the vulnerability of livestock to heat stress varies according to species, genetic potential, life stage and nutritional status. Increasing intensification of dairy systems in the developing world, through the use of temperate breeds should lead to greater vulnerability to increasing THI. Solutions opened embrace: the use of more adapted breeds like Australian Friesian, crossbreeding and adapting current production systems.

\section{CONCLUSION}

The new equation developed, in the present study, for estimating temperature-humidity index (THI) can be applied accurately for estimating THI under the Egyptian climatic conditions of the Nile Delta region. The results on the climate change indicate the continuity of increase in THI in the future (2025 and 2050). However, more meteorological studies using specialized simulation techniques are badly needed in this respect. The results should direct the attention of livestock breeders to respond properly and promptly to the climate change, especially during the hot season. Strategic options to face global warming may include breeding, feeding and managerial practices to restore efficiency of Holstein milk production in the Delta region of Egypt.

\section{ACKNOWLEDGEMENT}

The authors would like to thank Dina farm for Agricultural Investment, Sami Asaad farm and ElKarada farm for supplying milk production data. Also, the authors would like to thank the Central Laboratory for Agricultural Climate for providing the meteorological data.

\section{REFERENCES}

Ashour, G., R.R. Sadek , M.A.M. Ibrahim and A.M. Samoul, 2014. Effect of housing system on productive and reproductive performance of Holstein cows in a commercial herd in Egypt. Egyptian J. Anim. Prod., 51(2):79-87.

Berman, A. J., 2005. Estimates of heat stress relief needs for Holstein dairy cows. J. Anim. Sci., 83:1377-1384.
Bouraoui, R., M. Lahmar, A. Majdoub, M. Djemali and R. Belyea, 2002. The relationship of temperature-humidity index with milk production of dairy cows in a Mediterranean climate. Anim. Res., 51:479-491.

Elischer, M., 2014. History of dairy cow breedsHolstein. http://msue. anr.msu.edu/ news/history of dairy cow breeds holstein

El Raey, M., 2010. Impacts and implications of climate change for the coastal zones of Egypt. Coastal zones and climate change. http://www.stimson.org/images/uploads/researchpdfs/Mohamed.pdf

Elsharkawy, H., H. Rashed and I. Rached, 2009. Climate Change: The impacts of sea level rise on Egypt, $5^{\text {th }}$ ISOCARP Congress,

Ghavi Hossein-Zadeh, N., A. Mohit and N. Azad, 2013. Effect of temperature-humidity index on productive and reproductive performances of Iranian Holstein cows. Iranian J. Vet. Res., Shiraz Univ., 14(2):106-112.

Houghton, J.T., Y. Ding, D.J. Griggs, M. Noguer, P.J. van der Linden, X. Dai, K. Maskell and C.A. Johnson, 2001. Climate Change: The Scientific Basis. Contribution of working group I to the third assessment report of the Intergovernmental Panel on Climate Change. Cambridge Univ. Press, New York, U.S.A.

Kadzere, C.T., M.R. Murphy, N. Silanikove, and E. Maltz, 2002. Heat stress in lactating dairy cows: a review. Livest. Prod. Sci., 77: 59-91.

Mader, T.L., M.S. Davis and T. Brown-Brandl, 2006. Environmental factors influencing heat stress in feedlot cattle. J. Anim. Sci., 84:712-719.

Nardone, A., B. Ronchi, N. Lacetera and U. Bernabucci, 2006. Climate effects on productive traits in livestock. Vet. Res. Commun., 30:75-81.

Nigm, A.A., R.R. Sadek, Sherien A. Yassien, M.A.M. Ibrahim and M. A. El-Wardani, 2015. Effect of climate change on test-day milk yield of Holstein cows maintained in the Nile Delta of Egypt. Egyptian J. Anim. Prod., 52(2):113-121.

NOAA, 1976. Livestock hot weather stress. Regional operations manual letter C- 31-76. US Dep. Commerce, National Oceanic and Atmospheric Administration, Natl. Weather Service Central Region, Kansas City, Missouri (Cited by Ravagnolo et al., 2000).

Perkins, S., 2012. Latest news earth warming faster than expected. http://news.sciencemag. org/2012/ 03/earth-warming-faster-expected.

Ravagnolo, O., I. Misztal and G. Hoogenboomi, 2000. Genetic component of heat stress in dairy cattle, developed of heat index function. J. Dairy Sci., 83:2120-2125.

Sadek, R.R., G. Ashour, M.A.M. Ibrahim and A.M. Samoul, 2014. Effect of daily weight gain on age at first calving and subsequent milk yield of Holstein heifers in Egypt. Egyptian J. Anim. Prod., 51(3):164-171. 
Schaeffer, L.R. and J. Jamrozik, 1996. Multiple-trait prediction of lactation yields for dairy cows. J. Dairy Sci., 79: 2044-2055.

Singh, S.K., H.R. Meena, D.V. Kolekar and Y.P. Singh, 2012. Climate change impacts on livestock and adaptation strategies to sustain livestock production. J. Vet. Adv., 2(7):407-412.

Stanley, D. J. and A. G. Warne, 1993. Nile Delta: recent geological evolution and human impacts, Sci., 260 (5108), (Cited by El Raey, 2010).

Sterman, D., 2009. Climate change in Egypt: Rising sea level, dwindling water supplies. http://www. climate.org/topics/international-action/egypt.html
Thornton, P.K., J. Van de Steeg, A. Notenbaert and M. Herrero, 2009. The impacts of climate change on livestock and livestock systems in developing countries: A review of what we know and what we need to know. Agric. Sys., 101: 113-127.

XLSTAT, 2015. Statistical software for MS ExcelStatistical and data analysis with MS Excel. Addinsoft.

Yirka, B., 2012. New simulation predicts higher average earth temperatures by 2050 than other models. http://phys.org/news/2012-03-simulationhigher-average-earth-temperatures.html.

\footnotetext{
التغيرات المناخية المستقبلية وتأثيرها على إنتاج اللبن من ماثية الهولشتين المرباة فى دلتا النيل بمصر ربيع رجب صادق1، على عطيه نجم، شرين عبد الرحمن يس²، محمد عبد العزيز ابراهيم، محمد عبدالعزيز الوردانى2 1- قسم الإنتاج العيوانسي، كلية الزراعة، جامعة القاهرة، الجيزة، مصر، 2- قسم بحوث نظم الإنتاج، معهل بحوث الإنتاج الحيوانس، مركز

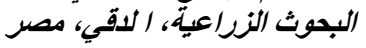

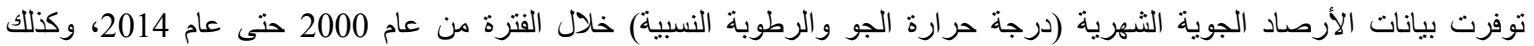

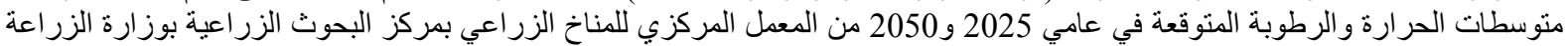

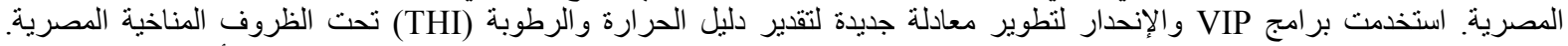

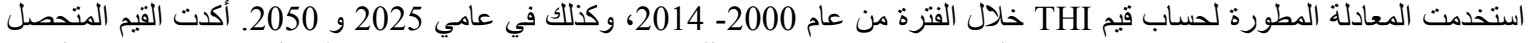

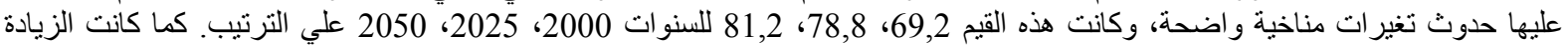

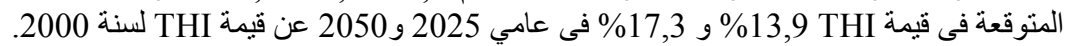

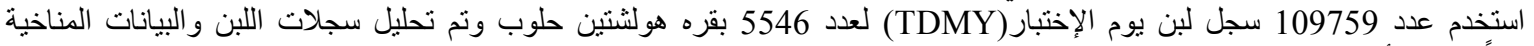

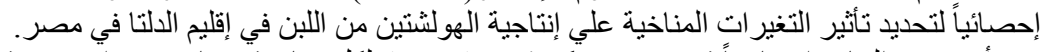
أوضحت النتائج إنخفاضاً قدره

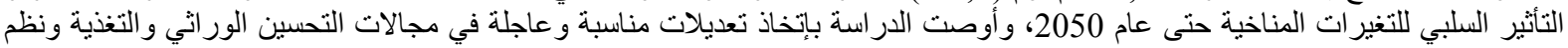
الإنتاج للمحافظة علي إنتاجية اللبن من الهوالشتين في منطقة دلتا النيل فى مصر.
} 